\title{
Lupinus mutabilis Edible Beans Protect against Bacterial Infection in Uroepithelial Cells
}

\author{
Witchuda Kamolvit, ${ }^{1}$ Vera Nilsén, ${ }^{1}$ Silvia Zambrana, ${ }^{2,3}$ Soumitra Mohanty, \\ Eduardo Gonzales, ${ }^{3}$ Claes-Göran Östenson, ${ }^{2}$ and Annelie Brauner $\left({ }^{1}{ }^{1}\right.$ \\ ${ }^{1}$ Department of Microbiology, Tumor and Cell Biology, Division of Clinical Microbiology, Karolinska Institutet and \\ Karolinska University Hospital, 17176 Stockholm, Sweden \\ ${ }^{2}$ Department of Molecular Medicine and Surgery, Karolinska Institutet and Karolinska University Hospital, 17176 Stockholm, Sweden \\ ${ }^{3}$ Area de Farmacologia, Instituto de Investigaciones Farmaco Bioquimicas, Facultad de Ciencias Farmacéuticas y Bioquimicas, \\ Universidad Mayor de San Andres, La Paz, Bolivia
}

Correspondence should be addressed to Annelie Brauner; annelie.brauner@ki.se

Received 29 July 2018; Revised 6 November 2018; Accepted 15 November 2018; Published 16 December 2018

Guest Editor: Constantinos Athanassopoulos

Copyright (C) 2018 Witchuda Kamolvit et al. This is an open access article distributed under the Creative Commons Attribution License, which permits unrestricted use, distribution, and reproduction in any medium, provided the original work is properly cited.

\begin{abstract}
Lupinus mutabilis is a South American herb with edible beans, known to reduce serum glucose levels in diabetic patients. Furthermore, L. mutabilis contains phytochemicals known to decrease bacterial load. Based on the increased urinary tract infections experienced among patients with diabetes, we investigated the effect of $L$. mutabilis on bladder epithelial cells in the protection of E. coli infection during normal and high glucose concentrations. We did not observe any direct antibacterial effect by $L$. mutabilis extract. Instead we observed an influence on the host cells, with indirect impact on bacteria and their possibility of causing infection. L. mutabilis extract decreased adhesion to bladder epithelial cells of uropathogenic bacteria, including drug-resistant strains. Moreover, uroplakinla, involved in adhesion, was downregulated while the antimicrobial peptide RNase 7 was upregulated in L. mutabilis treated cells irrespectively of glucose concentration. This supports an early effect fighting bacteria. Additionally, L. mutabilis prevented bacterial biofilm formation, which is used by bacteria to evade the immune system and antibiotics. In summary, L. mutabilis protects against bacterial infection in uroepithelial cells by preventing adhesion through alteration of the cell surface, increasing antimicrobial peptide expression, and reducing biofilm formation. Together, this promotes bacterial clearance, suggesting that L. mutabilis as extract or as a dietary item can contribute to the prevention of urinary tract infections, which is of importance in an era of increasing antibiotic resistance.
\end{abstract}

\section{Introduction}

Urinary tract infection (UTI) is one of the most common infections, with $E$. coli as leading etiological agent [1]. The frequency of recurrent infections is high and consequences, aside from vast medical expenses, include considerable suffering-especially among patients with chronic diseases. In fact, patients with diabetes run a tenfold higher risk of contracting UTI compared to healthy volunteers [2]. The reason is not yet fully understood but can partly be explained by glycosuria promoting bacterial growth, autonomic neuropathy in the bladder and urethra, as well as antimicrobial peptide expression deficiency [3-5]. A therapy that can target this vulnerable and increasing group of patients is important.

When bacteria infect the urinary bladder, they adhere to the uroepithelial cells by attaching to adhesion factors of the host cells [6]. Simultaneously the innate immune response is activated with production of antimicrobial peptides, cytokines, and chemokines. Antimicrobial peptides belong to a group of diverse, positively charged peptides that disrupt bacterial membranes by binding to them. Contrary to antibiotics where resistance frequently develops, resistance to antimicrobial peptides is rare [7]. To avoid the immune 
system, bacteria hide within bacterial biofilm or intracellularly, where the accessibility for antimicrobial therapy is decreased.

The emerging global antibiotic resistance calls for immediate action, and therefore traditional herbal therapies constitute an area of increasing research interest. To prevent infection, studies have focused on antivirulence factors of uropathogenic E. coli, by enhancing the endogenous immune response with substances such as traditional herbs and vitamins [8-10].

Lupinus mutabilis is part of the Lupinus family with over 200 different species, originally from the Andes, Bolivia. It is famous for its edible beans, traditionally used to secure dietary protein intake. The beans contain a high number of phytochemicals, triglycerides, proteins, and alkaloids, e.g., lupanine [11]. Lupanine has been shown to stimulate insulin secretion in a glucose-dependent manner in mice, and blood glucose lowering properties have been observed in dysglycemic persons $[12,13]$. Immune modulating properties have not been explored for L. mutabilis but their complex phytochemical components warrant further investigation and a potential role in preventing infections, e.g., UTI. Based on the antidiabetic effect of L. mutabilis, we investigated its effect on bladder infection in high glucose conditions, to mirror the diabetic condition.

The aim of this study was to examine the potential effects of Lupinus mutabilis extract on the interaction of uropathogenic bacteria and bladder epithelial cells using an in vitro model. We first investigated the bactericidal and biofilm preventing effects. Next the effect on the host antimicrobial peptide both under normo- and hyperglycemic conditions was studied.

\section{Materials and Methods}

2.1. Plant Material and Extraction. Plant specimen was collected from local producers from Ancoraimes Municipality, Omasuyos Province, La Paz, Bolivia (latitude $15^{\circ} 55^{\prime} 19.3^{\prime \prime} \mathrm{S}$ and longitude $68^{\circ} 53^{\prime} 50.1^{\prime \prime} \mathrm{W}$ ). One voucher specimen (No. EG-1, Fabaceae) was identified and certified by the Herbario Nacional de Bolivia from Universidad Mayor de San Andrés (UMSA) and has been deposited in the Department of Pharmacology at the Instituto de Investigaciones Farmaco Bioquimicas, UMSA, La Paz, Bolivia. L. mutabilis seeds (200 g) from the plant specimen were powdered and macerated in $70 \%$ ethanol solution for $48 \mathrm{~h}$ to prepare the hydroethanolic extract $(250 \mathrm{ml})$. To maximize the yield, the maceration procedure was repeated 5 times. Ethanol solvent was evaporated using a rotary evaporator (Heidolph, Schwabach, Germany) and the water fraction was dried under pressure in a freeze dryer (Labconco, Kansas City, MO, USA). Crude extracts obtained had an appearance of a yellow light powder with a yield of $22.0 \% \mathrm{w} / \mathrm{w}$. For experiments the extract was dissolved in distilled water, and stock solutions were sterilized by a $0.22 \mu \mathrm{m}$ Millipore filter prior to use.

2.2. Bacterial Strains. Escherichia coli No. 12, isolated from a child with acute pyelonephritis, was used for all infection experiments. It expresses type 1 fimbriae and is able to form biofilm [14]. Additionally, the following bacteria were used: Escherichia coli (ATCC 25922), ESBL (Extended Spectrum Beta-Lactamase) producing Escherichia coli (CCUG 55971) Klebsiella pneumoniae (ATCC 13883), multidrugresistant (MDR) Klebsiella pneumoniae (CCUG 58547), Proteus mirabilis (ATCC 29245), Pseudomonas aeruginosa (ATCC 27853), Enterococcus faecalis (ATCC 29212), Staphylococcus saprophyticus (ATCC 15305), and Streptococcus agalactiae (ATCC 13813). Prior to use, the bacteria were cultured at $37^{\circ} \mathrm{C}$ on Luria-Bertani (LB) or blood agar plates overnight.

2.3. Epithelial Cell Cultures. Human bladder epithelial cell lines T24 (HTB-4, ATCC) and 5637 (HTB-9, ATCC) were maintained in McCoy's 5A medium or RPMI 1640 (Gibco, Life Technologies, Paisley, UK), respectively, and supplemented with $10 \%$ fetal bovine serum (FBS) at $37^{\circ} \mathrm{C}$ with $5 \% \mathrm{CO}_{2}$. T24 and 5637 were also maintained in RPMI 1640 medium, no glucose (Gibco, Life Technologies, Paisley, UK), and supplemented with $10 \%$ FBS and $5 \mathrm{mM}$ glucose (SigmaAldrich, Schnelldorf, Germany). After overnight seeding into 24- or 96-well plates, cells were treated with $1000 \mu \mathrm{g}$ $/ \mathrm{ml}$ of $L$. mutabilis extract and supplemented with desired concentration of glucose $(5 \mathrm{mM}$ for normoglycemia and $\geq 11 \mathrm{mM}$ for hyperglycemia) $24 \mathrm{~h}$ prior to infection assay. Cells grown with medium alone served as controls.

2.4. Cell Viability Assay. The effect of L. mutabilis treatment on the viability of T24 and 5637 cells was determined at various concentrations and for different time points to evaluate the long term effect, in both cases using the XTT assay. Cells were treated with $L$. mutabilis extract at concentrations ranging from 300 to $20000 \mu \mathrm{g} / \mathrm{ml}$ for $24 \mathrm{~h}$ and for $24 \mathrm{~h}$, $48 \mathrm{~h}$, and $72 \mathrm{~h}$ with $1000 \mu \mathrm{g} / \mathrm{ml} \mathrm{L}$. mutabilis extract and then incubated with $250 \mu \mathrm{l}$ of $1 \mathrm{mg} / \mathrm{ml}$ XTT (Sigma-Aldrich, Schnelldorf, Germany) and $12.5 \mu \mathrm{M}$ menadione (SigmaAldrich, Schnelldorf, Germany) for $2 \mathrm{~h}$ according to the manufacturer's instructions. The conversion of tetrazolium salt XTT to a colored formazan derivative was measured at $490 \mathrm{~nm}$ in a 96-well plate. Nontreated control cells were maintained throughout the cell viability assay.

2.5. Adhesion and Invasion Assay. To evaluate the impact of L. mutabilis on the ability of uropathogens to adhere to uroepithelial cells, adhesion and rate of invasion assays were performed by infecting cells with $10^{6}$ of the previously mentioned bacteria, respectively, for $30 \mathrm{~min}$ in $37^{\circ} \mathrm{C}$ at $5 \%$ $\mathrm{CO}_{2}$. Thereafter, cells were washed with PBS to remove nonadherent bacteria. To collect cell associated bacteria, cells were lysed with $0.1 \%$ triton-X-100 in PBS. Lysates were plated on blood agar, and bacterial numbers were calculated after overnight incubation of serial dilutions. In the invasion assay, cells were infected and treated as in the adhesion assay. Thereafter fresh medium was added for $1 \mathrm{~h}$, followed by exposure to gentamicin $100 \mu \mathrm{g} / \mathrm{ml}$ for $30 \mathrm{~min}$ to kill extracellular bacteria. Finally, cells were washed with PBS, lysed, and plated as described for adhered bacteria. In treated cells, medium was supplemented with L. mutabilis throughout the 
entire experiment. Invasion rate was calculated by number of intracellular bacteria in relation to the total number of the adhered bacteria from the same experiment.

2.6. Antimicrobial Activity Assay. Direct antimicrobial activity of $L$. mutabilis was determined against the following bacteria: E. faecalis (ATCC 29212), E. coli (ATCC 25922), K. pneumoniae (ATCC 13883), P. mirabilis (ATCC 29245), P. aeruginosa (ATCC 27853), S. saprophyticus (ATCC 15305), and S. agalactiae (ATCC 13813). The minimum inhibitory concentration (MIC) of L. mutabilis was determined using a broth microdilution method in 96-well polystyrene microtiter plates according to the Clinical Laboratory Standards Institute (2016) guidelines, with some modifications. The stock solution of extract was serially twofold diluted in cationic adjusted Mueller Hinton broth (MHB) and the final concentration ranged from 50 to $0.2 \mathrm{mg} / \mathrm{ml}$. The final inoculum was $5 \times 10^{5} \mathrm{CFU} / \mathrm{ml}$.

2.7. Crystal Violet Assay. To investigate L. mutabilis extract effect on bacterial biofilm formation, crystal violet assay was used. E. coli No. $12\left(5 \times 10^{4} \mathrm{CFU} / \mathrm{ml}\right)$ was grown in LB broth without salt, supplemented with 0,5 , and $11 \mathrm{mM}$ glucose concentrations, and treated with L. mutabilis at concentrations of 400 and $1000 \mu \mathrm{g} / \mathrm{ml}$. After incubation at $37^{\circ} \mathrm{C}$ with $5 \% \mathrm{CO}_{2}$ for $72 \mathrm{~h}$, planktonic cells were removed, and wells were washed with PBS twice and then stained for 10 minutes with $0.3 \%$ crystal violet. After removing crystal violet and washing with tap water, a 1:5 solution ethanol and acetone was used to dissolve the remaining crystal violet stains from the biofilm formation. After shaking wells for $10 \mathrm{~min}$ in $200 \mathrm{rpm}$, the OD was analyzed using spectrophotometry at $570 \mathrm{~nm}$.

2.8. Total RNA Extraction, cDNA Synthesis, and Gene Expression Analysis. Total RNA was extracted from bladder epithelial cells using the RNeasy Mini Kit (Qiagen, Hilden, Germany) according to the manufacturer's protocol. Concentration and purity of RNA were determined using Nanodrop, and up to $1 \mu \mathrm{g}$ of RNA was transcribed to cDNA using the High-Capacity cDNA Reverse Transcription Kit (Applied Biosystems, Vilnius, Lithuania) [15]. Real-time PCR for caveolin-1 (CAV1, Hs00184697_m1), $\beta 1$ integrin (ITGB1, Hs00559595_ml), and uroplakinla (UPK1A, Hs00199638_ml) was analyzed using specific TaqMan gene expression assays (Applied Biosystems, Vilnius, Lithuania) in a Rotor-Gene PCR cycler (Corbett Life Science, Hilden, Germany). Human GAPD (GAPDH, 4326317E) and 18S (18s, Hs03003631_g1) were used as housekeeping controls. Furthermore, the antimicrobial peptides human cathelicidin LL-37 (CAMP, Hs00189038_m1) and psoriasin (S100A7, Hs00161488_m1); human $\beta$-defensin 2, DEFB4A_F ( $5^{\prime}$ - ccctttctgaatccgc) and DEFB4A_R ( $5^{\prime}$ - gagggtttgtatctcct); RNase 7, RNASE7_F ( $5^{\prime}$ ggagtcacagcacgaagacca) and RNASE7_R ( $5^{\prime}$ - catggctgagttgcatgcttga) were analyzed using $\mathrm{SYBR}{ }^{\circledR}$ Green specific primers. $\beta$-actin, ACTB_F ( $5^{\prime}$-aagagaggcatcctcaccct), and ACTB_R ( $5^{\prime}$-tacatcgctggggtgttg) served as housekeeping controls for comparison of cycle values. Relative expressions of target genes were presented as $2^{-\Delta \mathrm{CT}}$ and fold change as $2^{-\Delta \Delta \mathrm{CT}}$ compared to uninfected and nontreated control.

2.9. Immunofluorescence Staining of Cells. 5637 cells were treated with $1000 \mu \mathrm{g} / \mathrm{ml}$ of L. mutabilis for $24 \mathrm{~h}$ in both $5 \mathrm{mM}$ and $11 \mathrm{mM}$ cells. Cells were fixed in $4 \%$ PFA for $30 \mathrm{~min}$ at room temperature and permeabilized with $0.1 \%$ tritonX-100 in PBS. Permeabilized cells were blocked with 5\% BSA in PBS for $30 \mathrm{~min}$ at room temperature. Then cells were incubated overnight at $4^{\circ} \mathrm{C}$ with RNase 7 primary antibody (1:200, Icosagen) or uroplakinla (1:200, Santa Cruz) in $1: 1$ ratio of $1 \mathrm{X}$ PBS with $0.1 \%$ Tween 20 (PBS-T) and $5 \%$ BSA in PBS. Cells were washed with $1 \mathrm{X}$ PBS-T and further incubated with secondary Alexa Fluor-conjugated antibody (1:500, Invitrogen) for $1 \mathrm{~h}$ at room temperature and mounted in Fluoromount G (Southern Biotech). Slides were analyzed with a Leica SP5 confocal microscope using 63X oil immersion objective, from random view fields per coverslip.

2.10. Statistical Methods. Statistical analyses were performed using Graph Pad Prism Version 5.04 (GraphPad Software, San Diego, CA, USA). For comparison between treated and control groups, Student's unpaired t-test, one-way ANOVA, and post hoc Bonferroni test were used. Differences were considered significant if $\mathrm{p}$-value $=0.05$ or less.

\section{Results}

3.1. Effect of L. mutabilis on Uroepithelial Cells and Direct Antibacterial Properties on Common Uropathogenic Bacteria. Cell viability assay using XTT confirmed that $L$. mutabilis extract at concentrations up to $1000 \mu \mathrm{g} / \mathrm{ml}$ did not affect the viability of bladder epithelial cells, which remained $99 \%$ after $24 \mathrm{~h}$ of treatment. When increasing the concentration to $20 \mathrm{mg} / \mathrm{ml}$, the cell survival decreased to approximately $80 \%$ (Supplementary Figure 1(A)). A timescale cell growth assay was also performed up to $72 \mathrm{~h}$ with and without the extract, not showing any difference in growth pattern of L. mutabilis treated cells compared to untreated cells (Supplementary Figure 1(B)). This confirmed that L. mutabilis did not arrest the cell cycle nor affect vital aspects of cell metabolism. Furthermore, L. mutabilis extract did not have any bactericidal effect, when tested up to $125 \mathrm{mg} / \mathrm{ml}$ on E. coli, K. pneumoniae, P. mirabilis, P. aeruginosa, S. saprophyticus, and E. faecalis.

\subsection{L. mutabilis Extract Decreases Adhesion of Uropathogenic} Bacteria. After excluding that L. mutabilis had direct, bactericidal effect on uropathogenic bacteria, we investigated the possible indirect effector mechanisms. Adhesion is the critical, first step of infection in uroepithelial cells [16]. We observed that $1000 \mu \mathrm{g} / \mathrm{ml}$ treatment of L. mutabilis extract for $24 \mathrm{~h}$ prior to the infection significantly decreased the ratio of bacteria adhering to T24 bladder epithelial cells both at 5 and $11 \mathrm{mM}$ glucose, reflecting normoglycemic and hyperglycemic conditions. Such decrease was observed when testing the common uropathogenic bacteria E. coli, ESBL producing E. coli, K. pneumoniae, multidrug-resistant K. pneumoniae, 


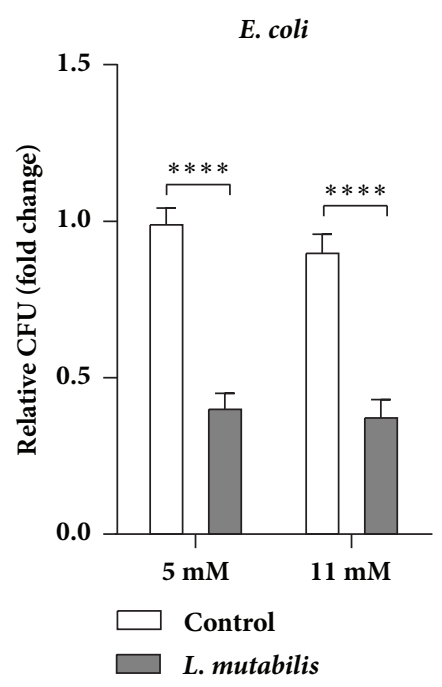

(a)

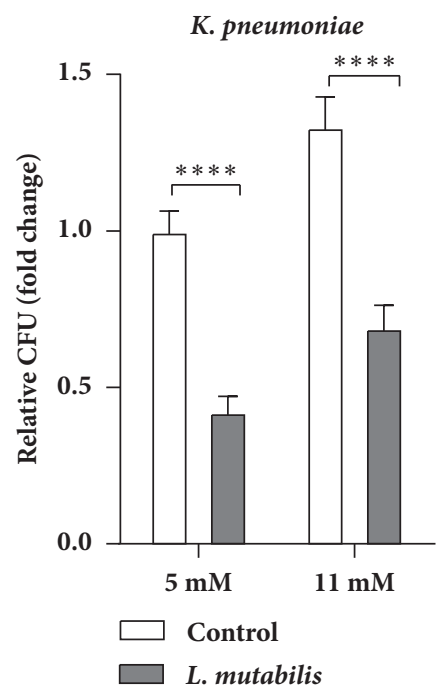

(d)

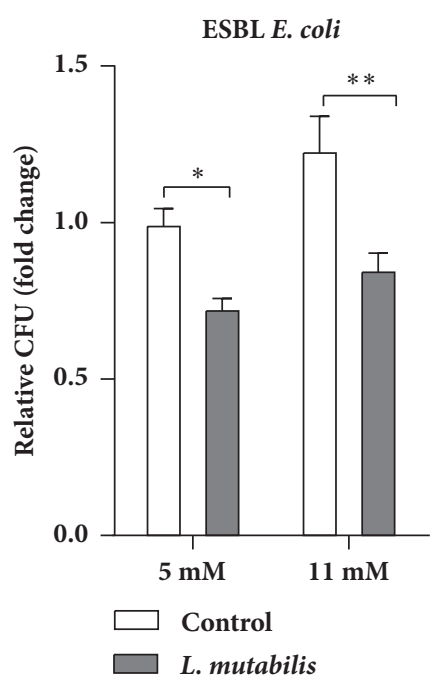

(b)

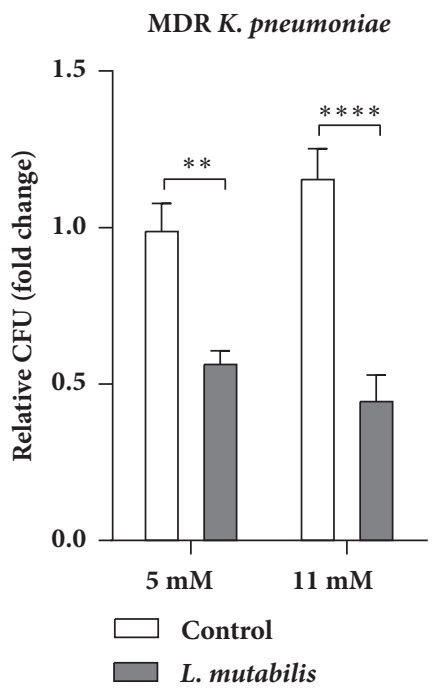

(e)

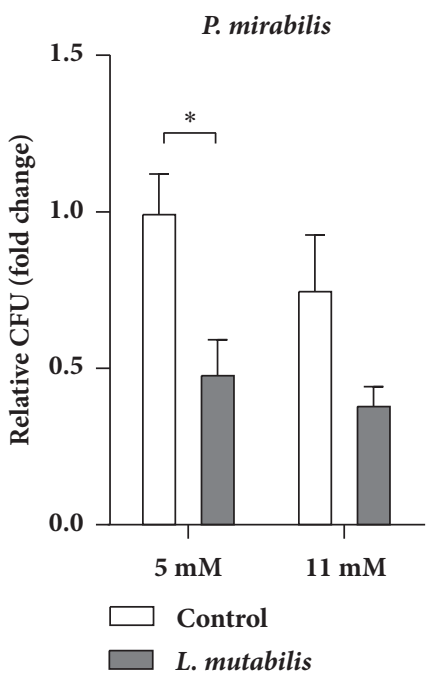

(c)

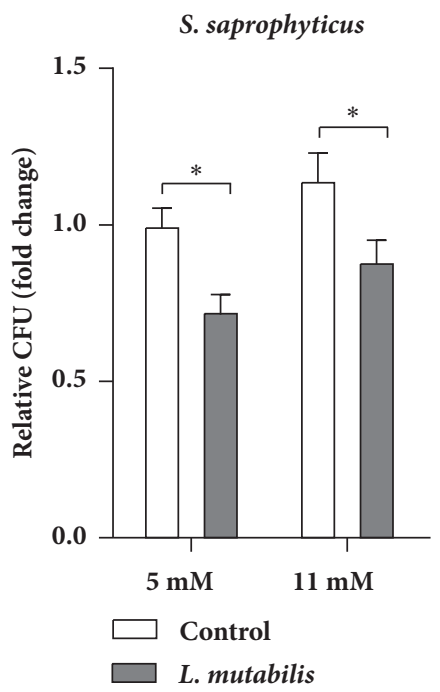

(f)

Figure 1: Adhesion assay. Pretreatment with L. mutabilis inhibits bacterial adhesion in bladder epithelial cells in $5 \mathrm{mM}$ and $11 \mathrm{mM}$ glucose concentrations. Adhesion assay was performed on T24 cells after prior treatment with $1000 \mu \mathrm{g} / \mathrm{ml}$ of L. mutabilis for $24 \mathrm{~h}$, followed by $30 \mathrm{~min}$ infection with the following bacteria: E. coli (a), extended spectrum beta-lactamase (ESBL) E. coli (b), P. mirabilis (c), K. pneumoniae (d), multidrug-resistant (MDR) K. pneumoniae (e), and S. saprophyticus (f). Data shown are +/- SEM. Results were normalized to nontreated uninfected control cells indicated by $\mathrm{P} *<0.05, \mathrm{P} * *<0.01$, and $\mathrm{P} * * * *<0.0001$. Data were calculated from at least two independent experiments with triplicates per condition. MDR refers to strain that is resistant to three or more antimicrobial classes.

P. aeruginosa, and S. saprophyticus (Figure 1). Moreover, $L$. mutabilis treatment significantly decreased the adhesion of P. mirabilis in normoglycemia. The invasion rate of the same uropathogens was not significantly changed after L. mutabilis treatment (data not shown).

3.3. L. mutabilis Alters Cell Surface Proteins and Expression of Antimicrobial Peptides in Uroepithelial Cells. One of the most common indirect antibacterial mechanisms, observed with the use of herbal extracts, such as C. bolivianum, is downregulation of cell surface proteins to which bacteria bind when adhering to the host cells [10]. The effects of uroplakinla (UPK1A), $\beta 1$ integrin (ITGB1), and caveolin-1(CAV1) were therefore investigated. We observed that the UPK1A mRNA was significantly decreased in pretreated uroepithelial cells (Figure 2(a)) with a similar trend on the protein level (Figure 2(b)), both at 5 and $11 \mathrm{mM}$ glucose. However, $L$. mutabilis pretreatment did not influence caveolin-1 or $\beta 1$ integrin expression (data not shown).

Interestingly, the antimicrobial peptide, RNASE7 mRNA, was significantly increased in bladder cells pretreated with L. mutabilis both in normal and high glucose concentrations (Figure $2(\mathrm{c})$ ), with similar results on the protein 


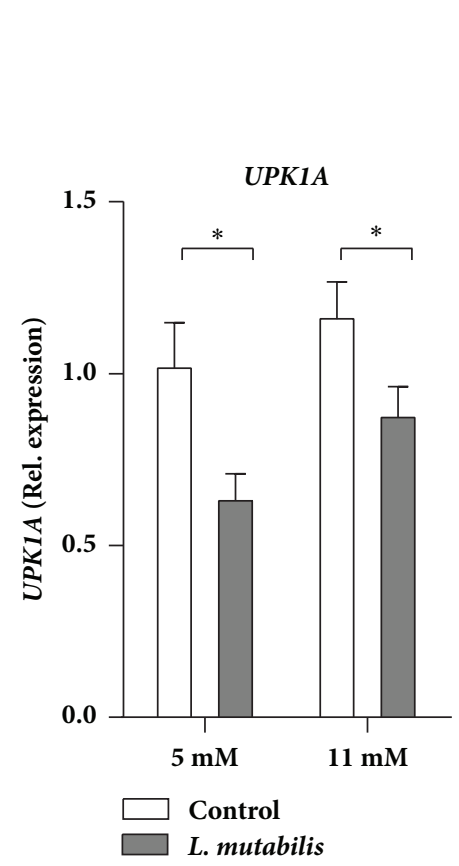

(a)

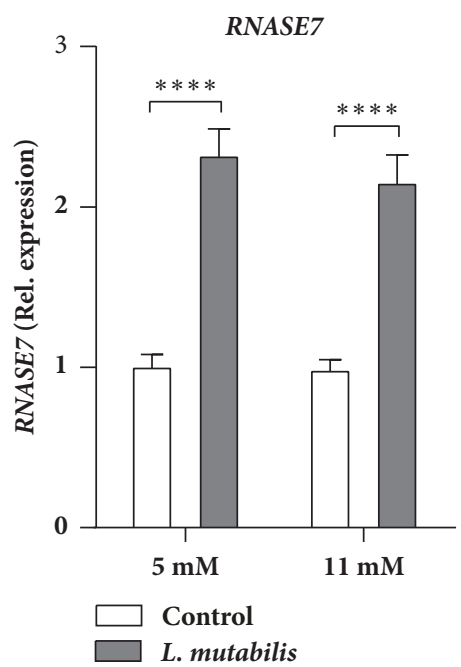

(c)
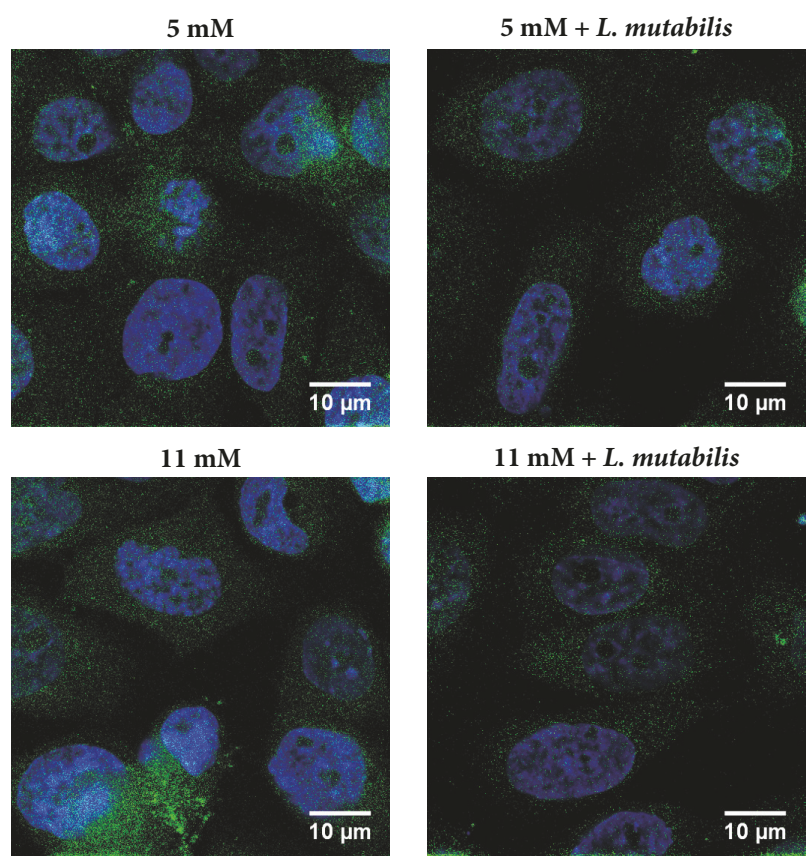

$11 \mathrm{mM}+$ L. mutabilis

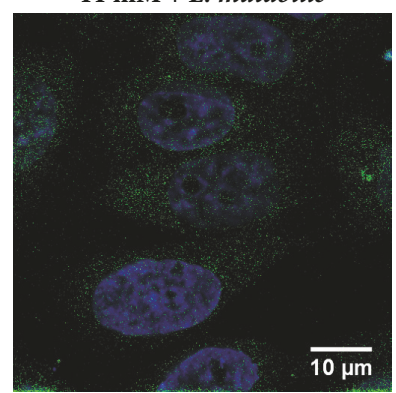

(b)
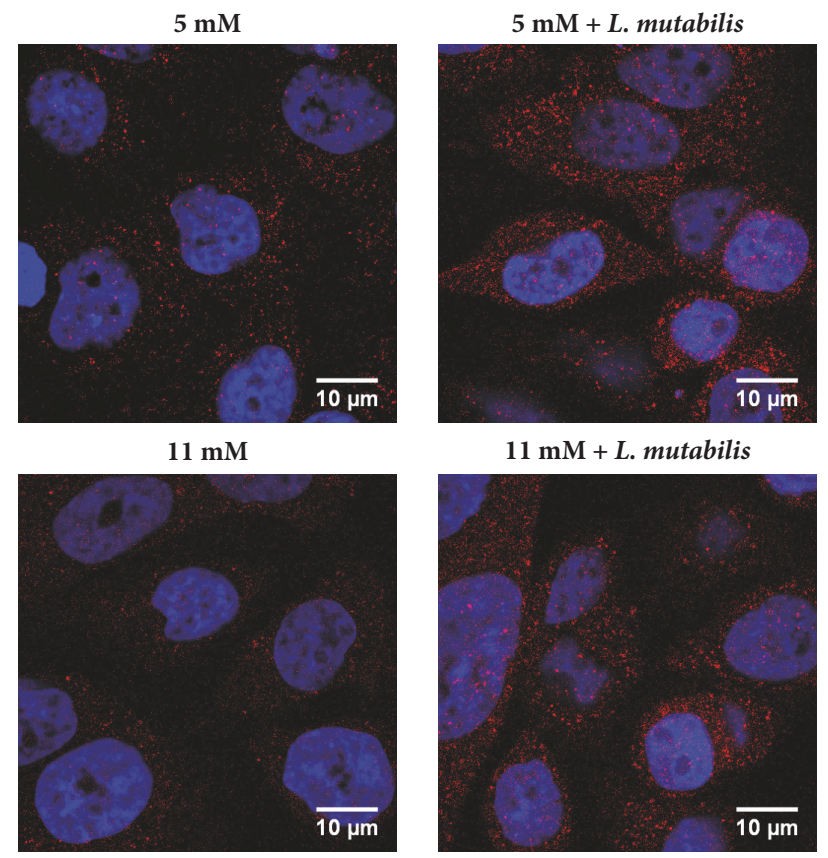

(d)

FIGURE 2: mRNA and protein expression of cell surface receptor and antimicrobial peptides in uninfected uroepithelial cells. Expression of UPK1A (a) and RNASE7 (c) at mRNA level in cells treated for $24 \mathrm{~h}$ with $1000 \mu \mathrm{g} / \mathrm{ml}$ of L. mutabilis in 5 and $11 \mathrm{mM}$ glucose and nontreated cells in equivalent glucose concentrations as control. Immunofluorescence staining also confirmed downregulation of UP1a (b) and upregulation of RNase 7 (d) after $24 \mathrm{~h}$ of $1000 \mu \mathrm{g} / \mathrm{ml}$ of L. mutabilis treatment in both 5 and $11 \mathrm{mM}$ cells when compared to respective control cells. Data shown are $+/$ - SEM. Results were normalized to nontreated uninfected control cells indicated by $\mathrm{P} *<0.05$ and $\mathrm{P} * * * *<0.0001$. Expression of mRNA was from a total of three independent assays with duplicates per condition.

level (Figure 2(d)). Expression of the antimicrobial peptides cathelicidin, LL-37 (CAMP), and human $\beta$-defensin 2, hBD-2 $(D E F B 4 A)$, at mRNA remained unchanged in the pretreated cells (data not shown).
3.4. L. mutabilis Extract Inhibits E. coli Biofilm Formation. E. coli forms biofilm as protection against innate immune responses and antibacterial therapies. Thereby bacteria become less accessible for antibiotics and may persist either 


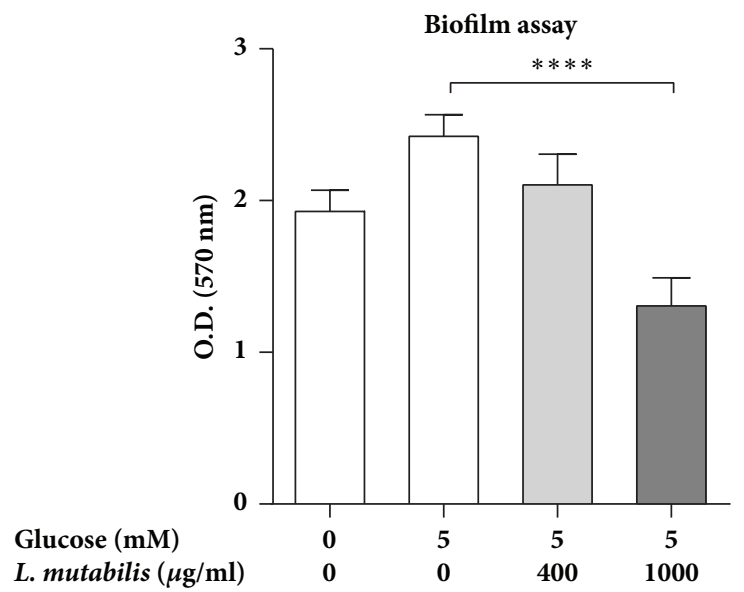

FIGURE 3: E. coli No. 12 biofilm adherence and thickness. Bacteria and L. mutabilis extract were added to LB medium without salt with supplementation of $0 \mathrm{mM}$ and $5 \mathrm{mM}$ of glucose, respectively. Bacteria were incubated with $5 \% \mathrm{CO}_{2}$ for $72 \mathrm{~h}$ before being washed and stained with crystal violet for spectrophotometry. Data shown are mean $+/$ - SEM. $* * * * \mathrm{P}<0.0001$. Biofilm assays were calculated from at least two independent experiments with six replicates per condition.

extracellularly or in the uroepithelial cells as intracellular bacterial communities, possibly reoccurring at a later time point [16]. Although L. mutabilis did not have bactericidal effect, we observed that treatment with $L$. mutabilis extract at concentration, $1000 \mu \mathrm{g} / \mathrm{mL}$, significantly reduced biofilm formation at normal glucose conditions, $5 \mathrm{mM}$ (Figure 3). However, in higher glucose concentrations, 11 and $30 \mathrm{mM}$, no significant effect of $L$. mutabilis was observed.

\section{Discussion}

Herbal extracts are frequently used in traditional medicine, although the underlying mechanisms are not always known. We here demonstrate that extract from L. mutabilis does not exhibit bactericidal effect. However, by blocking bacterial adhesion to the host cell, $L$. mutabilis efficiently prevents infection [16]. The decreased adhesion is due to downregulation of the cell surface protein, uroplakinla, which is pivotal for the initiation of bacterial infections in the urinary tract; this is similar to our earlier finding where two other plant extracts, Clinopodium bolivianum and Amaranthus caudatus, also decreased the adhesion and invasion by downregulating uroplakinla $[10,17]$. On the contrary, no effect was observed on caveolin 1 or $\beta 1$ integrin, both of them associated with invasion to host cells [16], supporting the assumption that L. mutabilis pretreatment solely acts on bacterial adherence. Bacteria are equipped with adhesins, out of which the type 1 fimbrial adhesin, FimH, is necessary for adhesion to occur. It binds to uroplakinla, which therefore is crucial for the infection process [18]. Because of its importance, FimH has attracted much attention. Blocking the effect of the FimH antigen using vaccine [19], or a molecule that specifically blocks FimH binding to the host, e.g., mannose has successfully been tried in mice and humans [20, 21]. Here we demonstrate a possible alternative mode of action, instead targeting the cell surface protein, uroplakinla.
Antimicrobial peptides kill bacteria extracellularly before they adhere to the epithelium [22]. Different plant extracts are known to upregulate host antimicrobial peptides; e.g., $A$. paniculata upregulates human $\beta$-defensin 2 in lung epithelial cells [23]. Interestingly, the antimicrobial peptide RNase 7 was upregulated in L. mutabilis pretreated cells, contrary to LL-37 and human $\beta$-defensin 2 . This indicates that pretreatment with $L$. mutabilis specifically targets RNase 7 to fend off bacteria adhering to the uroepithelial cell surface. Interestingly, RNase 7 is naturally expressed in uroepithelial cells and is known to have bactericidal effect on Gram-negative and Gram-positive bacteria as well as MDR strains [24-26], which is in line with our results. Decreased bacterial adhesion with L. mutabilis pretreatment as well as upregulation of RNase 7 expression was seen both in normal and hyperglycemic conditions, mimicking metabolic conditions in the urinary bladder of diabetic patients. This finding is of clinical interest because diabetic patients are known to have an impaired function of antimicrobial peptides such as RNase 7 due to lack of insulin [5].

Moreover, we observed that L. mutabilis reduces E. coli biofilm formation without inhibiting bacterial growth, suggesting an independent effect on biofilm formation. These findings are in line with our previous findings that subinhibitory concentrations of LL-37 reduced $E$. coli biofilm formation [14].

Chemical analysis of the L. mutabilis extract used in our study shows high triglyceride content and confirmed the presence of several bis-quinolizidine alkaloids, e.g., sparteine, lupanine, oxylupanine, 11,12-dehydrolupanine, and nuttalline [27], which is partly in agreement with previous data [11].

A limitation of the study is that the extract of L. mutabilis was used and not the different identified substances. Due to the complexity of the chromatogram, we decided to show a possible effect of the extract. It is likely that a combination of different already characterized and not yet characterized substances will be needed to reach optimal effect. 


\section{Conclusions}

In conclusion, our in vitro studies suggest that $L$. mutabilis prevents infections of uropathogenic bacterial strains, irrespective of glucose concentrations. This effect is mediated by downregulation of the cell surface protein, uroplakinla, and upregulation of the antimicrobial peptide RNase 7. Furthermore, bacterial biofilm formation is decreased, which may enhance the antibiotic effect. Taken together, pretreatment with extracts from $L$. mutabilis or L. mutabilis beans as a functional food item may in the future be used to prevent UTI in patients at increased risk. Future work will aim to study in vivo effect of $L$. mutabilis by using murine urinary tract infection model.

\section{Data Availability}

All the data supporting the results reported in the published article will be made available.

\section{Conflicts of Interest}

The authors declare no conflicts of interest.

\section{Authors' Contributions}

Witchuda Kamolvit and Vera Nilsén contributed equally to this paper.

\section{Acknowledgments}

This research was funded by Stockholm County Council (ALF project) (Annelie Brauner), Swedish Neurological Association (Neurofonden) (Annelie Brauner), and grants from Karolinska Institutet (Annelie Brauner, Soumitra Mohanty, and Witchuda Kamolvit) and the Swedish International Development Cooperation Agency (SIDA) (ClaesGöran Östenson, Eduardo Gonzales, and Silvia Zambrana). Silvia Zambrana is supported by grants from SIDA. WK is supported by grants from Siriraj Hospital Mahidol University, Thailand.

\section{Supplementary Materials}

Figure 1. Cytotoxic activity of L. mutabilis on bladder epithelial cells. (A) XTT assay was performed in T24 cells after treatment with L. mutabilis for $24 \mathrm{~h}$. Viability of treated cells were compared with respect to untreated control cells. (B) Timescale growth curve analyses of 5637 cells were performed up to $72 \mathrm{~h}$ and the viability was compared to the untreated control cells. Data shown are mean \pm SEM, from four independent experiments, performed in triplicate. $* * * * \mathrm{P}<0.0001$. (Supplementary Materials)

\section{References}

[1] B. Foxman, "The epidemiology of urinary tract infection," Nature Reviews Urology, vol. 7, no. 12, pp. 653-660, 2010.
[2] V. de Lastours and B. Foxman, "Urinary tract infection in diabetes: epidemiologic considerations," Current Infectious Disease Reports, vol. 16, no. 1, article 389, 2014.

[3] A. Brauner, U. Flodin, B. Hylander, and C. G. Östenson, "Bacteriuria, Bacterial Virulence and Host Factors in Diabetic Patients," Diabetic Medicine, vol. 10, no. 6, pp. 550-554, 1993.

[4] H. Brauner, P. Lüthje, J. Grünler et al., "Markers of innate immune activity in patients with type 1 and type 2 diabetes mellitus and the effect of the anti-oxidant coenzyme Q10 on inflammatory activity," Clinical \& Experimental Immunology, vol. 177, no. 2, pp. 478-482, 2014.

[5] T. E. Eichler, B. Becknell, R. S. Easterling et al., "Insulin and the phosphatidylinositol 3-kinase signaling pathway regulate Ribonuclease 7 expression in the human urinary tract," Kidney International, vol. 90, no. 3, pp. 568-579, 2016.

[6] D. S. Eto, T. A. Jones, J. L. Sundsbak, and M. A. Mulvey, "Integrin-mediated host cell invasion by type 1-piliated uropathogenic Escherichia coli," PLoS Pathogens, vol. 3, no. 7, pp. 0949-0961, 2007.

[7] M. Zasloff, "Antimicrobial peptides of multicellular organisms," Nature, vol. 415, no. 6870, pp. 389-395, 2002.

[8] O. Hertting, Å. Holm, P. Lüthje et al., "Vitamin D induction of the human antimicrobial peptide cathelicidin in the urinary bladder," PLoS ONE, vol. 5, no. 12, Article ID e15580, 2010.

[9] P. Lüthje, E. F. Lokman, C. Sandström, C.-G. Östenson, and A. Brauner, "Gynostemma pentaphyllum exhibits antiinflammatory properties and modulates antimicrobial peptide expression in the urinary bladder," Journal of Functional Foods, vol. 17, pp. 283-292, 2015.

[10] S. Mohanty, W. Kamolvit, S. Zambrana et al., "Extract of Clinopodium bolivianum protects against E. coli invasion of uroepithelial cells," Journal of Ethnopharmacology, vol. 198, pp. 214-220, 2017.

[11] F. E. Carvajal-Larenas, A. R. Linnemann, M. J. R. Nout, M. Koziol, and M. A. J. S. van Boekel, "Lupinus mutabilis: Composition, Uses, Toxicology, and Debittering," Critical Reviews in Food Science and Nutrition, vol. 56, no. 9, pp. 1454-1487, 2016.

[12] M. Fornasini, J. Castro, E. Villacres, L. Narvaez, M. P. Villamar, and M. E. Baldeon, "Hypoglycemic effect of lupinus mutabilis in healthy volunteers and subjects with dysglycemia," Nutrición Hospitalaria, vol. 27, no. 2, pp. 425-433, 2012.

[13] M. Wiedemann, C. M. Gurrola-Díaz, B. Vargas-Guerrero, M. Wink, P. M. García-López, and M. Düfer, "Lupanine improves glucose homeostasis by influencing KATP channels and insulin gene expression," Molecules, vol. 20, no. 10, pp. 19085-19100, 2015.

[14] Y. Kai-Larsen, P. Lüthje, M. Chromek et al., "Uropathogenic Escherichia coli Modulates Immune Responses and Its Curli Fimbriae Interact with the Antimicrobial Peptide LL-37," PLoS Pathogens, vol. 6, no. 7, p. e1001010, 2010.

[15] P. Luthje, H. Brauner, N. L. Ramos et al., "Estrogen supports urothelial defense mechanisms," Science Translational Medicine, vol. 5, no. 190, pp. 190ra80-190ra80, 2013.

[16] G. R. Nielubowicz and H. L. T. Mobley, "Host-pathogen interactions in urinary tract infection," Nature Reviews Urology, vol. 7, no. 8, pp. 430-441, 2010.

[17] S. Mohanty, S. Zambrana, S. Dieulouard et al., "Amaranthus caudatus extract inhibits the invasion of E. coli into uroepithelial cells," Journal of Ethnopharmacology, vol. 220, pp. 155-158, 2018. 
[18] G. Zhou, W.-J. Mo, P. Sebbel et al., "Uroplakin la is the urothelial receptor for uropathogenic: Escherichia coli: Evidence from in vitro FimH binding," Journal of Cell Science, vol. 114, no. 22, pp. 4095-4103, 2001.

[19] S. Langermann, R. Möllby, J. E. Burlein et al., "Vaccination with FimH adhesin protects cynomolgus monkeys from colonization and infection by uropathogenic Escherichia coli," The Journal of Infectious Diseases, vol. 181, no. 2, pp. 774-778, 2000.

[20] C. Jarvis, Z. Han, V. Kalas et al., "Antivirulence Isoquinolone Mannosides: Optimization of the Biaryl Aglycone for FimH Lectin Binding Affinity and Efficacy in the Treatment of Chronic UTI," ChemMedChem, vol. 11, no. 4, pp. 367-373, 2016.

[21] B. Kranjčec, D. Papeš, and S. Altarac, "D-mannose powder for prophylaxis of recurrent urinary tract infections in women: A randomized clinical trial," World Journal of Urology, vol. 32, no. 1, pp. 79-84, 2014.

[22] M. Chromek and A. Brauner, "Antimicrobial mechanisms of the urinary tract," Journal of Molecular Medicine, vol. 86, no. 1, pp. 37-47, 2008.

[23] Z.-J. Shao, X.-W. Zheng, T. Feng et al., "Andrographolide exerted its antimicrobial effects by upregulation of human $\beta$ defensin- 2 induced through p38 MAPK and NF-kB pathway in human lung epithelial cells," Canadian Journal of Physiology and Pharmacology, vol. 90, no. 5, pp. 647-653, 2012.

[24] B. W. Hayes and S. N. Abraham, "Innate Immune Responses to Bladder Infection," Microbiology Spectrum, vol. 4, no. 6, 2016.

[25] J. Lehmann, M. Retz, J. Harder et al., "Expression of human beta-defensins 1 and 2 in kidneys with chronic bacterial infection," BMC Infectious Diseases, vol. 2, article 20, 2002.

[26] J. D. Spencer, A. L. Schwaderer, H. Wang et al., "Ribonuclease 7 , an antimicrobial peptide upregulated during infection, contributes to microbial defense of the human urinary tract," Kidney International, vol. 83, no. 4, pp. 615-625, 2013.

[27] S. Zambrana, L. Lundqvist, O. Mamani, S. Catrina, E. Gonzales, and C. Östenson, "Lupinus mutabilis Extract Exerts an AntiDiabetic Effect by Improving Insulin Release in Type 2 Diabetic Goto-Kakizaki Rats," Nutrients, vol. 10, no. 7, p. 933, 2018. 


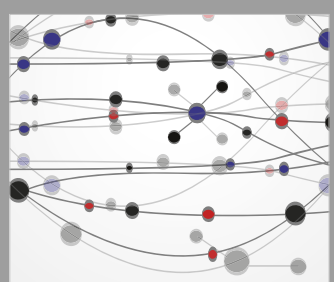

The Scientific World Journal
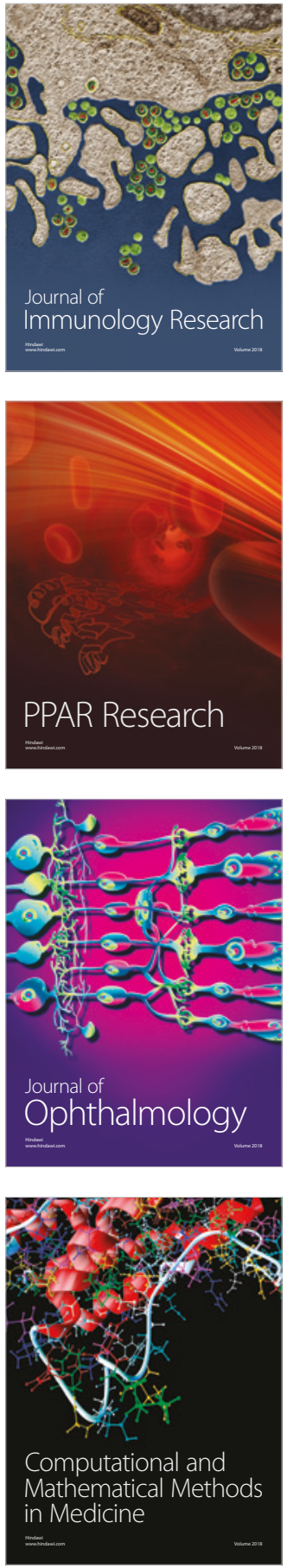

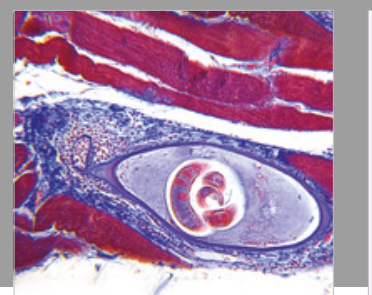

Gastroenterology Research and Practice

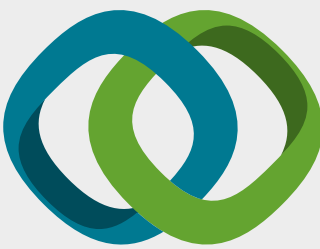

\section{Hindawi}

Submit your manuscripts at

www.hindawi.com
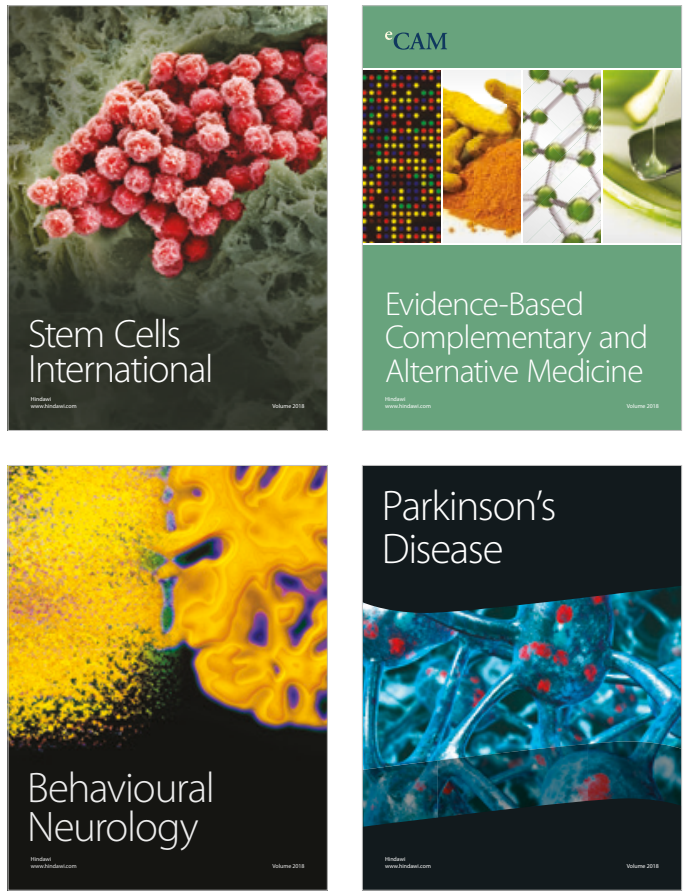

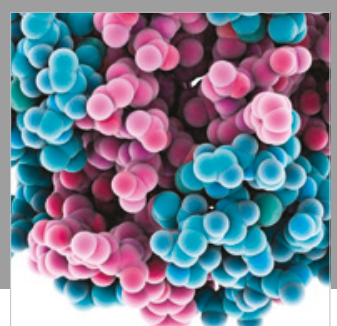

ournal of

Diabetes Research

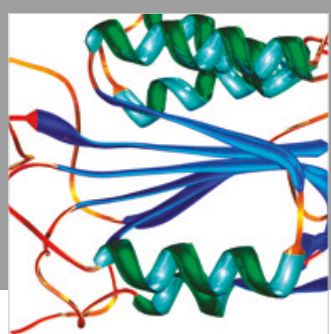

Disease Markers
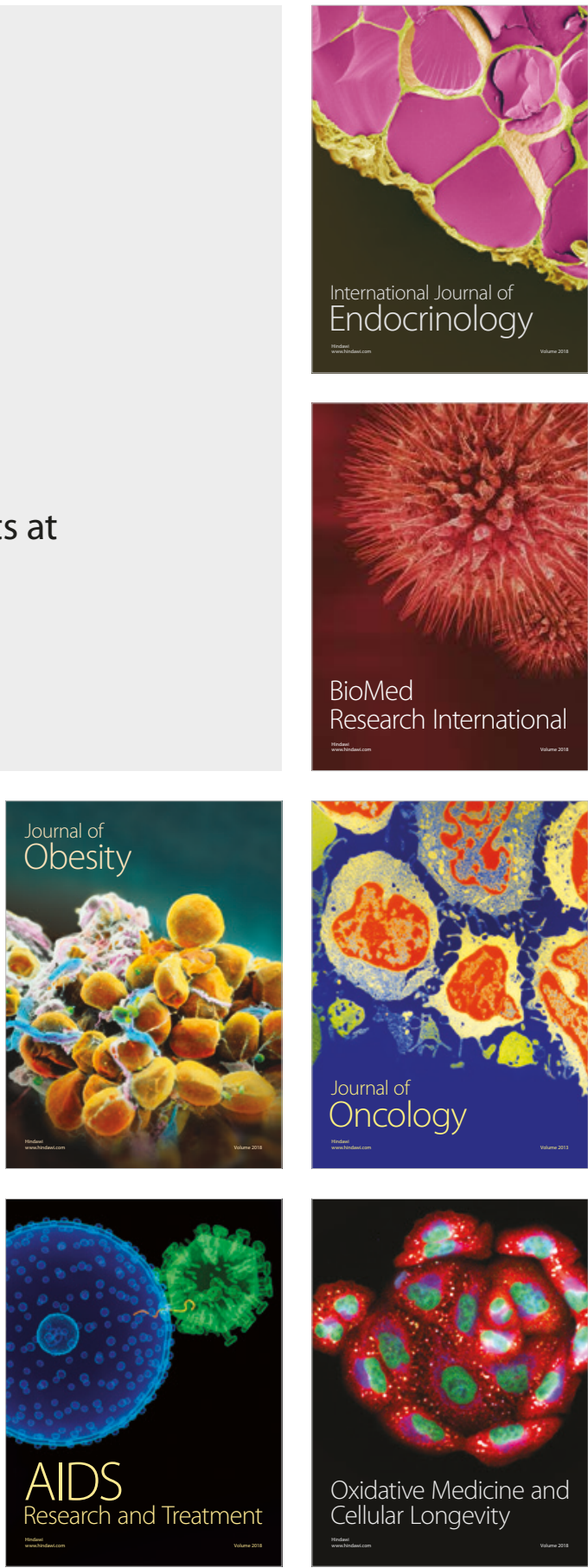